\title{
Irradiaciones y difuminaciones de la brutalidad en La condesa sangrienta y 2666
}

\section{Irradiation and fading of the brutality in La condesa sangrienta and 2666}

\author{
Alexis Candia-Cáceres \\ Centro de Estudios Avanzados (CEA), Univ. de Playa Ancha. Valparaíso, Chile. \\ ivan.candia@upla.cl
}

\section{Resumen}

Este artículo realiza un análisis comparativo entre La condesa sangrienta de Alejandra Pizarnik y el episodio protagonizado por la baronesa Von Zumpe y el general Entrescu en 2666. Para esto, se busca establecer las convergencias y divergencias que se producen entre ambos textos, poniendo el acento en la noción de brutalidad que tienen en común. Asimismo, se destaca el proceso inverso que aplican Pizarnik y Bolaño en la construcción del horror y del erotismo. Mientras La condesa sangrienta focaliza su interés en abordar el horror y desdibujar la sexualidad, el relato del castillo de Drácula apunta a solapar el mal e irradiar la voluptuosidad.

Palabras clave: La condesa sangrienta, 2666, análisis comparativo, brutalidad, horror.

\section{Abstract}

The article proposes a comparative analysis between La condesa sangrienta of Alejandra Pizarnik and the episode featuring for the Baroness Von Zumpe and general Entrescu in 2666. For this, we seek to establish the similarities and differences that occur between the two texts, emphasizing the notion of brutality they have in common. Also, applying the reverse process Pizarnik and Bolaño in the construction of horror and eroticism stands. While La condesa sangrienta focuses interest in explore the horror and blur sexuality, the story of Dracula's castle points to overlap the evil and radiate voluptuousness.

Keywords: La condesa sangrienta, 2666, Comparative Analysis, Brutality, Horror. 
¡Todo es espejo!

Octavio Paz.

2666 (2004) es el punto de encuentro de violencias fundamentales. Roberto Bolaño construye una novela donde emerge, atraviesa y explota la violencia, abrasando, inexorablemente, a decenas de personajes que cruzan por las peligrosas calles de ciudades de América, Europa y Asia. Las violencias fundamentales traspasan los cuerpos de las mujeres que son violadas, torturadas y ultimadas en Santa Teresa, pero, también, en la carne de aquellos hombres y mujeres que disfrutan de los delirios de erotismo extremo. La conexión entre muerte y erotismo no es antojadiza. De hecho las palabras iniciales de este artículo parafrasean una de las definiciones que Georges Bataille entrega no sobre el crimen o el mal sino sobre el erotismo ${ }^{1}$. Bataille asume que en el erotismo se cruza el poder germinativo de Eros con la violencia de Tánatos. Para Bataille, el erotismo se vincula con la agonía y el padecimiento propio del fin de la vida: "[...] el erotismo es la aprobación de la vida hasta en la muerte" (El erotismo 15). Eros y Tánatos parecen acariciarse, entonces, la punta de los dedos en la pieza central de la narrativa de Bolaño.

Ahora bien, hay otro texto literario hispanoamericano donde la conexión entre erotismo y muerte tiene un papel fundamental. Me refiero a La condesa sangrienta (1971) de Alejandra Pizarnik, ensayo poético sobre Erzsébet Báthory que la escritora argentina publicó a partir de la lectura del texto homónimo de Valentine Penrose ${ }^{2}$. Pizarnik reconfigura el reino subterráneo de la aristócrata húngara responsable de la muerte de 650 mujeres, plasmando la tortura, la muerte y el sadismo que llena las sombrías jornadas del castillo de Csejthe.

De esta forma, esta investigación apunta a explorar el vínculo que es posible establecer entre La condesa sangrienta y un episodio que transcurre en la región de Transilvania en "La parte de Archimboldi" de 2666, es decir, el encuentro de la baronesa Von Zumpe y el general Entrescu en el Castillo de Drácula. El feroz episodio lascivo bolañano dialoga, a todas luces, con el terrible erotismo, de nieve y murallas del texto de Pizarnik. Es más, hay una serie de elementos presentes en el episodio de 2666 que parecen influenciados por el discurso de la poeta argentina.

La condesa sangrienta y el encuentro de la baronesa Von Zumpe y el general Entrescu de 2666, están marcados por la presencia de la "brutalidad", vale decir, de la escenificación de la voluptuosidad a partir de un desequilibrio pasional que lleva a explotar las delicias de los cuerpos y que tiene a la violencia y a la crueldad como sellos de un rito que tiende hacia el exceso y el quiebre de los cánones morales y culturales

1 En El Erotismo (1957) Georges Bataille agrega, además, que: "El terreno del erotismo es esencialmente el terreno de la violencia, de la violación" (21).

2 Valentine Penrose publica Erzsébet Báthory, la comtesse sanglante en 1962 a través de Mercure de France. 
de la sociedad occidental. La brutalidad busca los límites del placer, apuntando a una liberación y a una revolución frente a las convenciones que rigen la forma de vivir y disfrutar del erotismo.

Hay críticos que han destacado la presencia de la ferocidad en ambos textos. Mientras Juan Carlos Galdo sostiene en "Fronteras del mal/ Genealogías del horror: 2666 de Roberto Bolaño” que las vidas de la baronesa Von Zumpe y del general Entrescu sirven "[...] para ilustrar la tenue línea que separa la transgresión sexual del crimen, el exceso" (32); Sara Toro Ballesteros sostiene en "Un híbrido de horror y belleza: La condesa sangrienta de Alejandra Pizarnik" que los límites del horror se traducen en una: "[...] desmembración textual en la que el propio contenido remite a la amputación que sufren las muchachas maltratadas por Báthory, que son sinécdoque de la Muerte, que a su vez es la intención escritural última de la autora y cuya representación y encarnación en la obra es la condesa" (102). Asimismo, se ha tratado la importancia que adquiere el erotismo en el desarrollo de ambos textos. Cabe destacar, en este sentido, que la revisión de la función de la sexualidad en $\mathrm{La}$ condesa sangrienta es mucho más profunda que en el episodio de la baronesa Von Zumpe en 2666. En "De Safo a Baffo: Diversiones de lo sexual en Alejandra Pizarnik" Sylvia Molloy establece que La condesa sangrienta plasma la sexualidad en su "[...] máxima violencia, para lograr la ruptura” (367). María Negroni propone, en la línea de Bataille, un cruce entre erotismo y muerte en el texto: "El impulso negador y la expresividad se entienden; la muerte fecunda al erotismo [...] la sexualidad tiene que ver con lo triste y, por ende, con la poesía" (175). La revisión del significado del episodio de Von Zumpe y Entrescu ha sido mucho más limitada, focalizando su interés especialmente en consignar el erotismo presente en la baronesa germana. De allí que el citado Galdo sostenga que: "En quien sí se manifiesta de manera central el culto a la voluptuosidad es en la figura de la baronesa Von Zumpe [...] Uno de los mejores pasajes del libro narra el encuentro entre la bella aristócrata y el general Entrescu en una cámara del castillo de Drácula” (31). Luis Martínez de Mingo establece, a su vez, la salvaje sexualidad presente en el encuentro de los Cárpatos: "No son menos hermosos los polvos sádicos y salvajes entre el general Entrescu y la baronesa Von Zumpe, allí en la galería de un castillo de los montes de Transilvania, mientras el general recita un poema incompresible, en el que solo se entiende cada cuatro versos la palabra Drácula" (296).

Ambos textos buscan, en consecuencia, cruzar los límites de lo permitido, de lo decible, sin embargo, no se puede soslayar que mientras uno (La condesa sangrienta) apunta, fundamentalmente, hacia Tánatos o más bien habría que decir hacia $\mathrm{Ker}^{3}$, el

3 A pesar de la comparación de Bataille, estoy convencido de que 2666 y La condesa sangrienta se relacionan mucho más con Ker que con Tánatos. Lo anterior responde a que mientras Tánatos responde a la idea de la muerte sin violencia marcada por su toque suave, Ker es la responsable de la muerte violenta. En El escudo de Heracles Hesiodo describe el accionar de Ker en la batalla de Heracles y Cicno. Allí sostiene que Ker: "[...] terrible se apoderaba de un vivo herido recientemente, o de otro sano y salvo o de un cadáver que arrastraba por los pies en medio de la 
otro (el episodio de Von Zumpe y el general Entrescu de 2666) se dirige hacia Eros. Bajo esta perspectiva, es dable sostener que ambos textos realizan movimientos contradictorios dado que mientras La condesa sangrienta ilumina la ejecución del horror y difumina la puesta en escena del erotismo, el episodio del castillo de Drácula en 2666 desvanece la puesta en escena del horror y focaliza la atención en la consumación del fenómeno erótico. De esta forma, los relatos de Bolaño y Pizarnik establecen una relación de convergencia/divergencia intertextual.

Para abordar el análisis de ambos textos son útiles los aportes que distintos autores han realizado en el ámbito de la literatura comparada. Asumo, en esta línea, una posición heterodoxa. Con relación a los métodos de análisis, Aldridge y Clements le dan relevancia a la comparación y la reconciliación como sus ejes centrales, hasta el punto que buscan la igualdad entre las unidades, la que se sustenta en la totalidad del objeto -la literatura universal o europea, por ejemplo- y que lleva a Curtius a afirmar que la literatura occidental forma una comunidad histórica y una unidad fundamental. En este contexto, Wellek y Warren llevan el cosmopolitismo hasta el paroxismo. No sólo abogan por la comprensión de la literatura como una totalidad, sino que demandan la supresión de la autonomía local. Asimismo, consideran las literaturas nacionales como simples contribuciones a la literatura universal. Ciertamente, tal percepción de la literatura elimina cualquier tipo de diferencia y otredad en el método de la literatura comparada. Además, hablan del lenguaje de la coacción y del control, considerando, por ejemplo, el carácter imperativo de los géneros sobre los creadores. Wellek y Warren redujeron a las obras, los autores y las literaturas nacionales a partes o contribuciones de la norma general.

Ante ese modelo de la literatura comparada, Gilbert Chaitin opondrá una literatura diferencial que no sólo cuestiona la unidad de esa literatura general, sino que modificó substantivamente su método de análisis, remplazando la búsqueda de la homogeneidad por la persecución de la otredad. Bajo este prisma, adquiere relevancia la séptima hipótesis de Parménides, la que, por cierto, apunta a que lo individual -especialmente su autosuficiencia- es producto de las diferencias con los otros y, en consecuencia, la totalidad dependiente de la otredad. Chaitin propone, en suma, un enfoque tendiente a dar un giro a la visión tradicional de la literatura comparada, concentrada, tradicionalmente, en la búsqueda de semejanzas y en la construcción de generalidades, a fin de establecer las diferencias y, especialmente, las otredades que existen entre las literaturas locales.

refriega. Su traje manchado de sangre humana flotaba en torno a sus hombros, miraba ella con ojos espantosos y prorrumpía en clamores" (23). Más adelante agrega una descripción aún más contundente: “[...] las Keres negras de voces broncas y rostro terrible, fatales e insaciables, se disputaban a los que caían, y todas deseaban beber la sangre negra y coger al primero que cayera herido. Y extendían sus largas uñas sobre él, con el fin de llevarse el alma al Hades y hacia el Tártaro helado. Luego, con objeto de saciarse de sangre humana, arrojaban el cadáver detrás de sí, y se abalanzaban de nuevo a la refriega" (24). La estética brutal que adopta Ker se relaciona muchísimo más con la condesa sangrienta que la muerte apacible ejecutada por Tánatos. 
La utilización de una mirada heterodoxa en los aportes de la literatura comparada responde a las demandas que realiza el estudio de la literatura de Pizarnik y Bolaño. Mientras el enfoque de Aldridge, Clements, Wellek y Warren es útil para abordar a las protagonistas, los espacios, la presencia de la sangre y la oscuridad de ambos textos, donde la búsqueda de la reconciliación es altamente recomendable, la posición de Chaitin es adecuada para abordar el juego de difuminaciones e iluminaciones del erotismo y el horror.

\section{Oscura simetría}

La condesa sangrienta y el episodio de los Cárpatos de 2666 están protagonizados por nobles europeas que no solo detentan una posición social y económica privilegiada, la que les permite deambular libremente por los territorios del mal y el placer, sino que poseen una considerable belleza de la que emerge el poder de seducción que irradian hacia los hombres y las mujeres que se cruzan en sus caminos. Así, Pizarnik destaca que Valentine Penrose concentra su interés en narrar: "[...] la belleza convulsiva del personaje” (Pizarnik párr. 3). Y luego agrega que Báthory es parte central de un mundo donde: "[...] la siniestra hermosura de las criaturas nocturnas se resume en una silenciosa palidez legendaria, de ojos dementes, de cabellos del color suntuoso de los cuervos" (Párr. 4). En 2666 se destaca, también, la belleza de la baronesa Von Zumpe. El texto se detiene en la impresión que le produce a Reiter el reencuentro con la noble germana: "Le pareció hermosísima, mucho más que cuando la conoció" (849).

Ambos textos comparten, además, el hecho de construir "reinos subterráneos", donde la presencia del castillo y del laberinto juega un rol preponderante en el desarrollo de las acciones. No es casual que Roberto Bolaño sitúe el encuentro de Von Zumpe y Entrescu en la región donde se origina y está ambientada la leyenda y la literatura sobre el conde Drácula. Bolaño dialoga constantemente durante este episodio con la mitología que rodea al noble rumano Vlad Tepes. Tanto el espacio en que se sitúa la acción como las conversaciones, discusiones y menciones en torno a Drácula por parte de los miembros del Tercer Reich que se alojan en el castillo rumano aluden, una y otra vez, a la figura central del vampirismo. De esta forma, Bolaño introduce la seducción, la pasión y la crueldad -elementos que simboliza el empalador rumano- como aderezos de la ardiente y sofocante noche protagonizada por Von Zumpe y Entrescu.

Aun cuando las alusiones a Drácula son explícitas y se reiteran, una y otra vez, en "La parte de Archimboldi", Bolaño alude, soterradamente, a otra figura de Transilvania tan relacionada con el erotismo, la sangre y el mal como Drácula, pero que resulta mucho menos conocida: Erzsébet Báthory. La narración de Bolaño mantiene numerosos elementos en común con la leyenda abordada por la poeta argentina Alejandra 
Pizarnik en La condesa sangrienta, lo que contribuye a acrecentar los alcances de la brutalidad desplegada por el general rumano y la aristócrata germana.

Las conexiones entre 2666 y La condesa sangrienta pasan, también, por el espacio donde se desarrolla la acción: un castillo de los Cárpatos. No se puede soslayar que esta región y, en especial, Transilvania, está marcada por un poderoso imaginario dominado por el ocultismo: "Leo que todas las supersticiones conocidas en el mundo están reunidas en la herradura de los Cárpatos, como si fuese el centro de alguna especie de remolino imaginativo" (Stocker 10), dice una de las anotaciones del diario de vida de Jonathan Harker. Desde luego, esas supersticiones están articuladas en torno a la figura y el terror que despierta el vampiro.

Bolaño y Pizarnik ponen a sus personajes en un castillo. Mientras Bolaño los sitúa en el castillo de Drácula, Pizarnik hace transcurrir la acción en el castillo de Csejthe, lugar donde, en efecto, residió Erzsébet Báthory. Isabel Monzón sostiene, en este sentido, que el castillo: “[...] simboliza un lugar de protección, al ser una morada sólida y de difícil acceso. Precisamente por estar en general situado en las alturas, queda aislado" (Monzón). De esta forma, el castillo es un lugar separado del resto del mundo que adquiere un aspecto inaccesible pero a la vez deseable. Probablemente ningún autor plantea de manera tan profunda e inquietante la dialéctica aislamiento/deseo que evoca esta construcción arquitectónica como Franz Kafka en El castillo, texto en el que K intenta variadas estratagemas para acceder al recinto, evidenciando el deseo de penetrar en esos dominios, las que, a la larga, resultan inútiles: el agrimensor no puede cruzar el cerco que rodea al edificio.

La concepción arquitectónica de Kafka subraya, entonces, la enorme privacidad que impone el castillo. Al situarse en un lugar aislado, éste permite ignorar las normas que rigen a la sociedad, transformándose en un espacio abierto a la transgresión y al crimen. De ahí que Sade emplace la acción de las 120 jornadas de Sodoma en un remoto castillo situado en las montañas y rodeado de bosques, debido a que estaba desligado del mundo y así los cuatro crápulas podían dedicarse a realizar las atrocidades que habían planificado con tanta detención. Erzsébet Báthory utiliza el castillo -al igual que los libertinos de Sade- como un refugio que le permite ejercer la violencia: asesina a 650 mujeres en el castillo de Csejthe. En este sentido, Csejthe es el refugio necesario para realizar su mal:

Castillo de piedras grises, escasas ventanas, torres cuadradas, laberintos subterráneos, castillo emplazado en la colina de rocas, de hierbas ralas y secas, de bosques con fieras blancas en invierno y oscuras en verano, castillo que Erzébet Báthory amaba por su funesta soledad de muros que ahogaban todo grito (Pizarnik párr. 33).

El castillo de Drácula ocupado por Von Zumpe y Entrescu es, también, un lugar aislado y de difícil de acceso. Sin embargo, ni Von Zumpe ni Entrescu tienen intención alguna de seguir los senderos del mal abiertos por Báthory; la pareja emplea la privacidad de 
la propiedad para realizar una portentosa exhibición de la pasión y la violencia que encierra una de las formas de Venus: la brutalidad.

Bolaño lleva al lector hasta los aposentos de los amantes a través del recorrido que realizan los soldados Reiter y Wilke, quienes tienen que cruzar numerosos pasadizos para encontrar el objeto deseado: la baronesa Von Zumpe, mujer cuya belleza los ha deslumbrado: "Finalmente, tras cruzar otros puntos de vigilancia sumidos en la oscuridad y el sueño, llegaron a donde en verdad querían llegar, a la habitación iluminada por nueve velas de la baronesa Von Zumpe" (863). Reiter y Wilke transitan un laberinto para alcanzar a Von Zumpe, es decir, un complejo entramado arquitectónico que, según Chevallier y Gheerbrandt, tiene por objetivo crear: “[...] en el espacio más pequeño posible, el enredo más complejo de senderos, con la finalidad de retrasar la llegada del viajero al centro que desea alcanzar" (Cit. en Monzón). Alejandra Pizarnik relata, también, en La condesa sangrienta como Erzsébet Báthory deambula por un laberinto hasta alcanzar la habitación en que inmolaba los cuerpos de las muchachas que estaban a su servicio:

De haberlo querido, hubiera podido realizar su "gran obra" a la luz del día y diezmar muchachas al sol, pero le fascinaban las tinieblas del laberinto que tan bien se acordaban a su terrible erotismo, de nieve y de murallas. Amaba el laberinto, que significa el lugar típico donde tenemos miedo; el viscoso, el inseguro espacio de la desprotección y del extraviarse (Párr. 34).

Ambos autores ponen de manifiesto como el laberinto retrasa el encuentro del objeto deseado. Los soldados alemanes y Báthory persiguen, por supuesto, objetivos distintos. Bolaño los hace caminar hacia Eros; Pizarnik hacia Ker. Reiter y Wilke enfrentan una enorme precariedad sexual que los insta a perseguir a través de un viejo castillo el cuerpo de una hermosa y desinhibida aristócrata germana. Báthory desciende el laberinto, más bien, para tomar la sangre de las jóvenes que llegaban a servir al castillo.

\section{Tipos de sangre}

La baronesa von Zumpe y la condesa Báthory tienen conductas disímiles que están marcadas por las concepciones que cada una tiene sobre la vida. Mientras la aristócrata germana está movida por el hedonismo, la húngara está motivada por la melancolía. Ambas concepciones vitales las llevan, evidentemente, a adoptar diferentes formas de encarar el placer y el horror.

La amante de Entrescu asume, en este sentido, que la cultura es el placer, “[...] lo que proporcionaba y daba placer, y el resto era charlatanería” (Bolaño 853). En una conversación que sostiene con Archimboldi años después del episodio de los Cárpatos, reconoce la preeminencia de la consumación del deseo en su forma de entender la vida y, sobre todo, el cuestionamiento interno que siente al haber tenido 
una experiencia vital marcada por el goce en el momento en que Europa sucumbía al horror: "La baronesa [...] le confesó que a veces intentaba arrepentirse del goce que había experimentado durante aquellos años, pero que más que intelectualmente, o tal vez sería más apropiado decir moralmente, rechazaba esa actitud hedonista, la verdad era que su memoria, al evocarlos, aún se estremecía de placer” (1015-16). Así, la actitud de la baronesa Von Zumpe se conecta con la jouissance, es decir, el regocijo abordado por Roland Barthes en El placer del texto. A diferencia del plaisir -que está unido al goce cultural de la identidad de un movimiento homogeneizante del ego-, la jouissance es aquel tipo de placer que disipa y fracciona dicha identidad. Para Barthes, la jouissance tiene que ver con: "[...] la euforia, el colmo, el confort (sentimiento de completud donde penetra libremente la cultura), del sacudimiento, del temblor, de la pérdida propios del goce" (33-4).

La responsable de las muertes de 650 mujeres está influenciada, más bien, por la melancolía. La condesa sangrienta afirma que la melancolía está determinada por un problema de color y música. Para Pizarnik un color invariable rige al melancólico: “[...] su interior es un espacio de color de luto; nada pasa allí, nadie pasa. Es una escena sin decorados donde el yo inerte es asistido por el yo que sufre por esa inercia" (Párr 25). Sin embargo, la melancolía se trata, sobre todo, de un problema musical:

[...] una disonancia, un ritmo trastornado. Mientras afuera todo sucede con un ritmo vertiginoso de cascada, adentro hay una lentitud exhausta de gota de agua cayendo de tanto en tanto. De allí que ese afuera contemplado desde el adentro melancólico resulte absurdo e irreal y constituya "la farsa que todos tenemos que representar". Pero por un instante -sea por una música salvaje, o alguna droga, o el acto sexual en su máxima violencia-, el ritmo lentísimo del melancólico no sólo llega a acordarse con el del mundo externo, sino que lo sobrepasa con una desmesura indeciblemente dichosa; y el yo vibra animado por energías delirantes (Ibíd.).

La "bilis negra" estuvo asociada hasta la primera parte del siglo XVII con la depresión, la que marca un punto de quiebre entre el sujeto y la sociedad. De ahí que la propia Pizarnik subraye que en la época de Báthory la persona que estaba inmersa en el estado melancólico vivía, además, “[...] poseída por el demonio” (Pizarnik párr. 26).

Las disímiles perspectivas de las dos nobles europeas son claves para entender los movimientos de irradiación y difuminación que realizan respecto de la ejecución del horror y el erotismo. Ahora bien, ambos textos tienen un núcleo estético-teórico común que permite comprender la estética y la ética asociada a las concepciones de La condesa sangrienta y el episodio de los Cárpatos en 2666, el que, a todas luces, está marcado por las propuestas del Marqués de Sade y por ciertas lecturas que se han desarrollado sobre el sadismo. A partir de ese tronco común se produce una bifurcación que lleva a rutas separadas a la baronesa Von Zumpe y a la condesa Báthory. 
Alejandra Pizarnik introduce la historia de Báthory de la siguiente forma: "Sentada en su trono, la condesa mira torturar y oye gritar. Sus viejas y horribles sirvientas son figuras silenciosas que traen fuego, cuchillos, agujas, atizadores; que torturan muchachas, que luego las entierran [...] Esta sombría ceremonia tiene una sola espectadora silenciosa" (Párr. 6). El texto de Pizarnik focaliza su interés en el horror que la condesa despliega al interior del castillo de Csejthe, el que está motivado, en primer término, por la melancolía de la condesa y, en segundo término, por el deseo de preservar su belleza. Con relación a este primer punto, no se puede soslayar que la destrucción de los cuerpos femeninos constituye una "terapia" que contiene los padecimientos de la aristócrata húngara:

Pero hay remedios fugitivos: los placeres sexuales, por ejemplo, por un breve tiempo pueden borrar la silenciosa galería de ecos y de espejos que es el alma melancólica. Y más aún: hasta pueden iluminar ese recinto enlutado y transformarlo en una suerte de cajita de música con figuras de vivos y alegres colores que danzan y cantan deliciosamente (Párr. 25).

A ello es necesario agregar que la condesa Báthory cura sus dolores de cabeza asumiendo una actitud que, claramente, puede situarse dentro de las fronteras de la licantropía: “[...] cuando, vencida por sus terribles jaquecas, debía quedarse en cama, les mordía los hombros y masticaba los trozos de carne que había podido extraer. Mágicamente, los alaridos de las muchachas le calmaban los dolores" (Pizarnik párr. 20).

A lo anterior, es necesario sumar la obsesión que despierta la sangre en Báthory. La condesa sangrienta relata cómo la noble húngara se baña con la sangre de las mujeres asesinadas para evitar los efectos del envejecimiento de su cuerpo y, en consecuencia, para mantener la belleza. Influenciada por viejas hechiceras -Dorkó y Darvulia- se sume en las artes oscuras a fin de sortear los embates de la decrepitud y la muerte. De ahí que, por ejemplo, lleva escrito en un viejo pergamino la siguiente plegaria: "Isten, ayúdame; y tú también, nube que todo lo puede. Protégeme a mí, Erzébet, y dame una larga vida" (Párr. 28). La oración a Isten -que en húngaro significa dios-subraya el ardiente deseo de desafiar a la muerte por parte de la condesa:

[...] para preservar su lozanía, tomaba baños de sangre humana. En efecto, Darvulia, como buena hechicera, creía en los poderes reconstitutivos del "fluido humano". Ponderó las excelencias de la sangre de muchachas -en lo posible vírgenes- para someter al demonio de la decrepitud y la condesa aceptó este remedio como si se tratara de baños de asiento. De este modo, en la sala de torturas, Dorkó se aplicaba a cortar venas y arterias; la sangre era recogida en vasijas y, cuando las dadoras ya estaban exangües, Dorkó vertía el rojo y tibio líquido sobre el cuerpo de la condesa que esperaba tan tranquila, tan blanca, tan erguida, tan silenciosa (Pizarnik párr. 31). 
La condesa Báthory goza con los placeres sádicos que libera sobre las mujeres y, a su vez, construye un ritual al bañarse en su sangre para prolongar su juventud: "La sangre manaba como un geiser y el vestido blanco de la dama nocturna se volvía rojo. Y tanto, que debía ir a su aposento y cambiarlo por otro" (Párr. 11). La "jaula mortal” es, en este sentido, una de las herramientas predilectas de la condesa a la hora de aunar el despliegue de horror y la perpetuación de la fuerza vital:

Rojo atizador en mano, Dorkó azuza a la prisionera quien, al retroceder $-y$ he aquí la gracia de la jaula-, se clava por si misma los filosos aceros mientras su sangre mana sobre la mujer pálida que la recibe impasible con los ojos puestos en ningún lado. Cuando se repone de su trance se aleja lentamente. Han habido dos metamorfosis: su vestido blanco, ahora es rojo y donde hubo una muchacha hay un cadáver (Pizarnik párr. 10).

Además de los artilugios barrocos empleados para el asesinato de las mujeres, tales como la "jaula mortal", la "virgen de hierro", la muerte por agua o congelamiento, Báthory despliega, en términos de Pizarnik, un "estilo de torturar monótonamente clásico" que se puede resumir de la siguiente forma:

Se escogían varias muchachas altas, bellas y resistentes -su edad oscilaba entre los 12 y los 18 años- $y$ se las arrastraba a la sala de torturas en donde esperaba, vestida de blanco en su trono, la condesa. Una vez maniatadas, las sirvientas las flagelaban hasta que la piel del cuerpo se desgarraba y las muchachas se transformaban en llagas tumefactas; les aplicaban los atizadores enrojecidos al fuego; les cortaban los dedos con tijeras o cizallas; les punzaban las llagas; les practicaban incisiones con navajas (si la condesa se fatigaba de oír gritos les cosían la boca; si alguna joven se desvanecía demasiado pronto se la auxiliaba haciendo arder entre sus piernas papel embebido en aceite) (Pizarnik párr. 11).

El estilo de tortura desplegado por Báthory se conecta con la manera de entender el mal de uno de los principales estetas de la iniquidad: el Marqués de Sade. A pesar de que Báthory antecede históricamente al noble francés y, en consecuencia, el influjo debiera proyectarse desde la condesa hacia el marqués, creo que existe una influencia inversa en cuanto los textos de Sade -pienso esencialmente en las Las 120 jornadas de Sodoma, publicada en 1904- anteceden a la obra de las autoras que se hacen cargo de la historia de la condesa sangrienta. Por lo demás, la forma de operar de Pizarnik encaja con el frenesí sádico que consiste en: “[...] enumerar, hasta el agotamiento, las posibilidades de destruir a los seres humanos, de destruirlos y gozar con el pensamiento de su muerte y de su sufrimiento" (La literatura y el mal 88). Bernard Sichère establece, por su parte, que en Sade: “[...] se percibe una especie de obsesión por la purificación feroz y el impulso de agotar todas las figuras de la violencia, violencia que incluye en sus puestas en escena soñadas más o menos todas las prácticas de castigo y de suplicio conocidas hasta entonces en la historia de los hombres" (168). 
Ahora bien, la lectura más útil para analizar la conexión del texto de Pizarnik y Sade la efectúa Gilles Deleuze en "Coldness and cruelty”. Deleuze realiza un lúcido análisis comparativo entre las obras de Sade y Sacher-Masoch. La lectura de Deleuze establece que el trabajo de Sade no apunta a la aniquilación por la aniquilación sino que en último término tiende, sobre todo, a la negación en el más amplio y profundo sentido, es decir, busca la concreción del mal absoluto. Deleuze considera que el "héroe sadiano" ejecuta el mal a partir de un doble movimiento que apunta a condensar y acelerar la ejecución del crimen. Erzébet Báthory despliega un proceso análogo en La condesa sangrienta, el que la lleva a acrecentar constantemente el número de víctimas. Al igual que en Sade se produce un ansia por multiplicar de manera constante el número de crímenes, ampliando, incesantemente, el horror. Sin embargo, no se puede pasar por alto que mientras la frialdad y la crueldad sadiana está movida por el anhelo de alcanzar el mal absoluto, en La condesa sangrienta este proceso responde al deseo de postergar y disipar los síntomas de la melancolía y de evitar el envejecimiento y la muerte.

Bajo esta perspectiva, es claro que Pizarnik busca iluminar el horror desplegado por Erzébet Báthory, descendiendo a las tinieblas que se acoplaban a la puesta en escena de su teatro del espanto. Así, Pizarnik dirige su mirada hacia el mal, el horror y la perversión que están presentes en los cientos de crímenes efectuados por la aristócrata húngara. Roberto Bolaño opera de una forma distinta en el episodio del castillo de Drácula. Principalmente, porque la amplia exploración del mal que Bolaño realiza en $2666^{4}$ es suspendida, momentáneamente, en la visita de Von Zumpe al castillo de Drácula. En medio de la barbarie y del holocausto de la Segunda Guerra Mundial, Bolaño detiene la indagación del mal para construir un pequeño oasis que se centra en abordar las delicias de la carne. Sin embargo, no deja de ser atractivo que el fabuloso encuentro dionisiaco de la pareja de amantes esté inmerso en una celebración a la que asisten no solo diversos jerarcas del ejército alemán y rumano sino que incluso un oficial de las SS, es decir, del cuerpo de combate responsable de numerosos crímenes de guerra e incluso de la eliminación de judíos y gitanos. De esta forma, Bolaño difumina la exploración del mal, lo saca de escena, pero éste sigue

4 Para abordar este punto se puede revisar el artículo "Todos los males el mal. La "estética de la aniquilación" en la narrativa de Roberto Bolaño". En este trabajo se realiza una amplia exploración del mal en la narrativa de Roberto Bolaño y, específicamente, en 2666. Allí, se establece que la presencia del mal en la literatura de Roberto Bolaño puede ser leída a partir de lo que se denomina como la "Estética de la Aniquilación": "Cuando Bolaño aborda los asesinatos de judíos en la Segunda Guerra Mundial, los crímenes de la dictadura militar chilena o la historia de las mujeres asesinadas en Santa Teresa no está sino plasmando esa "Estética de la Aniquilación" que tiene que ver con poner en escena las múltiples formas de destruir totalmente al otro, estableciendo como el horror y la violencia son parte del engranaje que ha movido, en cierta medida, la historia occidental durante los últimos siglos. Bolaño produce una "Estética de la Aniquilación" que está compuesta por un recorrido por terrenos estériles que adolecen de falta de belleza o humor y en donde la devastación es el sino que mueve a numerosos personajes. No siempre la aniquilación será total en las novelas de Bolaño, sin embargo, cada vez que se pongan en marcha los mecanismos de la "Estética de la Aniquilación" hombres y mujeres padecerán la fuerza de quienes trazan los senderos del mal". Candia Cáceres, Alexis. "Todos los males el mal. La "estética de la aniquilación" en la narrativa de Roberto Bolaño". Revista Chilena de Literatura 76 (2010). 
estando allí, latiendo, como una fuerza que tarde o temprano termina manifestándose en el desarrollo del texto y que, en el caso de la novela mamut, estalla con fuerza al conocer, por ejemplo, la historia de Leo Sammer.

Inversamente a la ejecución del horror en 2666 y La condesa sangrienta, el tratamiento de erotismo tiende a iluminarse en la novela de Bolaño y, por el contrario, a difuminarse en la construcción literaria de Pizarnik. De esta forma, lo que Bolaño aborda desde un primerísimo primer plano, es decir, con una perspectiva casi pornográfica, es desenfocado en la historia de la aristócrata húngara.

Ahora bien, es interesante considerar que tanto el episodio del castillo de Drácula como el de Csejthe están construidos sobre una multiplicidad de miradas sobre el fenómeno erótico. Bolaño construye un episodio que cuenta con un doble foco de atracción. En primer plano, encontramos la portentosa exhibición erótica de Von Zumpe y el general Entrescu y, en segundo plano, hallamos la actitud voyerista de Reiter y Wilke:

Cubierta por un hombre desnudo con abundancia de vello en la parte su perior de la espalda y en las piernas descubrieron a la baronesa Von Zumpe, cuyos rizos rubios y parte de la frente altísima sobresalían ocasionalmente por debajo del hombro izquierdo de quien la estaba embistiendo. Los gritos de la baronesa al principio alarmaron a Reiter, que tardó en comprender que eran gritos de placer y no de dolor. Cuando el apareamiento terminó el general Entrescu se levantó de la cama y lo vieron caminar hasta una mesa en donde descansaba una botella de vodka. Su pene, del que colgaba una nada despreciable cantidad de secreción seminal, aún estaba erecto o semierecto y debía medir unos treinta centímetros (863-864).

La baronesa Von Zumpe no se baña con la sangre de otras -como lo hace Báthory-sino que abre sus propias venas a fin de no ahogarse en el enorme placer que le devora las entrañas, mutilando su propio cuerpo con el objeto de sortear el goce que padece su cuerpo:

[...] tras beber un vaso de Vodka volvió al lecho en donde la baronesa Von Zumpe dormitaba y, tras cambiarla de posición, empezó a follársela de nuevo, al principio con movimientos imperceptibles, pero después con violencia tal que la baronesa, de espaldas, para no chillar se mordió la palma de la mano hasta hacerse sangre. A esas alturas Wilke se había desabrochado la bragueta y se masturbaba apoyado en el muro. Reiter lo oyó gemir a su lado [...] al cabo de un rato él también empezó a tocarse, primero con discreción, por encima, después abiertamente, sacándose el pene y acomodándolo al ritmo del general Entrescu y de la baronesa Von Zumpe, que ahora ya no se mordía la mano (una mancha de sangre había crecido en la sábana, junto a sus mejillas sudorosas) sino que lloraba y decía palabras que ni el general ni ellos entendían, palabras que iban más allá de Rumania, incluso más allá de Alemania [...] más allá de 
lo que ellos, Wilke y Reiter, tal vez no el general Entrescu, entendían por amor, por deseo, por sexualidad (864-865).

Von Zumpe y el general Entrescu excitan los sentidos de los soldados, los que, por cierto, no pueden evitar dar curso a su propia sexualidad. Así, Bolaño intenta crear lo que está fuera de escena -lo obsceno- disolviendo el límite de la voluntad de los amantes, llevándolos a la expresión de una libertad feroz que se traduce en la explosión de sensaciones que saturan sus sentidos y que alcanza el exceso cuando la baronesa Von Zumpe "baña" con su sangre el cuerpo de Entrescu:

[...] y después la baronesa Von Zumpe pidió un vaso de Vodka, y después vieron a Entrescu y a la baronesa abrazados, de pie, cada uno sosteniendo con aire absorto sus respectivos vasos, y después Entrescu recitó un poema en su lengua, que la baronesa no entendió pero cuya musicalidad alabó, y después Entrescu cerró los ojos y fingió que escuchaba algo, la música de las esferas, y luego abrió los ojos y se sentó junto a la mesa y puso a la baronesa encima de su verga otra vez erecta [...] y recomenzaron los gritos y los gemidos y los llantos, y mientras la baronesa descendía por la verga de Entrescu o mientras la verga de Entrescu ascendía al interior de la baronesa Von Zumpe, el general rumano emprendió un nuevo recitado, recitado que acompañaba con el movimiento de ambos brazos (la baronesa agarrada a su cuello), un poema que una vez más ninguno de ellos entendió, a excepción de la palabra Drácula, que se repetía cada cuatro versos [...] poema que la joven baronesa, sentada a horcajadas sobre las piernas de Entrescu, celebraba cimbrándose hacia atrás y hacia delante, como una pastorcilla enloquecida en las vastedades de Asia, clavándole las uñas en el cuello a su amante, untando de sangre las comisuras de sus labios, sin que por ello Entrescu dejara de recitar ese poema (865).

La escenificación erótica realizada por Von Zumpe y Entrescu se sitúa, a todas luces, en el terreno de las prácticas sadomasoquistas, especialmente, por la brutalidad que adquiere el contacto físico entre los amantes. En El malestar en la sexualidad. Signifcados, mitos y sexualidades modernas Jeffrey Weeks establece que el sadomasoquismo se ubica en los límites de la sexualidad aceptable. Para Weeks dos características claves de la política S/M son su subjetividad, con la insistencia puesta en el significado de la situación, tal como la ven sus practicantes; y su énfasis en la elección, en el derecho a involucrarse en situaciones extremas para obtener placer. La subjetividad y la elección se implican mutuamente, pues la afirmación propone que el S/M es sólo realmente válido en situaciones de consenso entre iguales, mientras que la elección es esencial para la erotización de la situación porque para el S/M entusiasta, el sadomasoquismo no se trata del sufrimiento o del dolor, sino de la erotización ritualista del deseo de sufrimiento y dolor, del placer como realización de fantasías prohibidas y de las diferencias de poder como significantes del deseo: 


\begin{abstract}
Demuestra, en suma que el placer no está limitado a una parte del cuerpo, o a un orificio, o a una serie determinada de actividades sexuales, sino que podemos erotizar prácticas diversas en situaciones altamente ritualizadas. Los rituales son, de hecho, una clave para realzar el placer; y la prácticas, no importa cuán diversas y exóticas, prohibidas o extremas sean, se convierten en "metáforas para abandonarse al placer sexual" (379-380).
\end{abstract}

El delirio erótico montado por Von Zumpe y Entrescu puede asumirse como la ejecución de una práctica S/M tanto por la violencia que adquiere la cópula como por el ritual que escenifican la baronesa alemana y el general rumano. En este sentido, se encuentra el espacio escogido por Bolaño, el castillo de Drácula, la invocación al empalador rumano a través del poema declamado por Entrescu y, sobre todo, la sangre, elemento que tiene la peculiaridad de poseer una doble connotación: simboliza a la vida y a la muerte: "Para los cristianos, la sangre que fluye de las llagas de Cristo y que se recoge en el grial es el brebaje de la inmortalidad [...] Para la Biblia la sangre evoca la muerte pero también es la vida” (Monzón).

Bolaño y Pizarnik ponen la sangre como un sello distintivo de los personajes. Pero, si Von Zumpe deja fluir el exceso de vida que recorre su cuerpo ante el vértigo de la voluptuosidad, Báthory se sume en el "lago de todas las fuerzas" para extender su vida: “[...] la Condesa pensaba de las jóvenes: su sangre no las llevará más allá; la que va a vivir ahora de ella soy yo" (Monzón). Báthory se convierte, entonces, en una vampira, es decir, es una figura que se caracteriza por extraer algo (sangre y juventud) del otro. Von Zumpe se relaciona más bien con la vampiresa, es decir, la mujer “[...] que extrema el refinamiento de sus atributos para interesar y rendir a los hombres o a aquella de gran atractivo físico, con gran poder sobre el varón. La vampiresa es, a todas luces, una figura erótica que alimenta, con su imagen y sus conductas, el deseo del otro" (Monzón). La baronesa Von Zumpe es una mujer hermosísima que no sólo fascina a Entrescu sino también a Reiter y Wilke. Asimismo, es una aristócrata culta y refinada que puede pasearse por las más variadas temáticas y que, a su vez, se abre a experimentar distintas formas del placer sin sentir ninguna clase de límite o restricción. Por último, es claro que aumenta el deseo de los otros: la imagen final de Von Zumpe desparramando sangre sobre los labios de Entrescu constituye una poderosa imagen de la brutalidad. Aunque la vampira y la vampiresa le dan un significado distinto a la sangre, vinculado con Eros y Ker, respectivamente, no podemos obviar la conexión que existe entre la conducta de ambas mujeres. Más aún, luego de haber revisado la visión de Bataille y las conexiones que establece entre muerte y erotismo. Bajo esta óptica, se ubica la apreciación de Alejandra Pizarnik sobre la relación placer-muerte que subyace en la conducta de Báthory:

El desfallecimiento sexual nos obliga a gestos y expresiones del morir (jadeos y estertores como de agonía, lamentos y quejidos arrancados por el paroxismo). Si el acto sexual implica una suerte de muerte, Erzsébet Báthory necesitaba de 
la muerte visible, elemental, grosera, para poder, a su vez, morir de esa muerte figurada que viene a ser el orgasmo (Párr. 13).

La condesa sangrienta, al igual que el episodio protagonizado por Von Zumpe y Entrescu en 2666, opta por construir el fenómeno erótico a partir de una mirada voyeurística. Sylvia Molloy sostiene, en este sentido, que: "En realidad, esa mirada, claramente voyeurista, está compuesta de sucesivas miradas femeninas" ("De Safo a Baffo" 135). Con esa afirmación Molloy se refiere a la mirada de Pizarnik hacia la novela de Penrose y al vistazo de Penrose sobre la vida de Báthory y, a su vez, a la ojeada de Báthory en los cuerpos de las mujeres torturadas e inmoladas por su voluntad: "[...] su placer erótico proviene principalmente del espectáculo de la tortura de mujeres, de la sistemática penetración de carnes de mujeres llevada a cabo por ella misma, por sus sirvientas o por máquinas ingeniosas como la Virgen de Hierro" (134). No por nada la propia Molloy subraya la relevancia que adquiere el verbo contemplar en el desarrollo del texto. Báthory penetra con su mirada, ya sea desde su trono o el coche, los cuerpos de las mujeres. Ciertamente, resulta interesante considerar que en la mayoría de las torturas, Báthory obliga a las mujeres a desnudarse, lo que tiene un doble significado: erótico y mortal ${ }^{5}$. De hecho, la más benigna de sus torturas implica que éstas trabajen desnudas ante la condesa:

Las muchachas sobrellevaban con penoso asombro esta condena indolora pues nunca hubieran creído en su posibilidad real. Oscuramente, debían de sentirse terriblemente humilladas pues su desnudez las ingresaba en una suerte de tiempo animal realzado por la presencia "humana" de la condesa perfectamente vestida que las contemplaba (Pizarnik párr 13).

Lejos del profundo ardor heterosexual que emana del encuentro erótico de Von Zumpe y Entrescu, Pizarnik elabora más bien un relato de profundas resonancias femeninas: "En lo esencial, (Báthory) vivió sumida en un ámbito exclusivamente femenino. No hubo sino mujeres en sus noches de crímenes" (Párr. 22). Sylvia Molloy establece, en esta línea, que La condesa sangrienta: "[...] es un texto de transacciones textuales femeninas y sólo femeninas, de una mirada femenina y sólo femenina. (De igual modo hubiera podido decir: éste es un texto de transacciones sexuales femeninas y sólo femeninas, de una mirada erótica femenina y sólo femenina.)" (134). Así, La condesa sangrienta está en las antípodas del abierto y explícito erotismo de 2666, debido a que emplea, más bien, una lubricidad borrosa y ambigua, indicando, soterradamente, el lesbianismo de la condesa Báthory:

Porque nadie tiene más sed de tierra, de sangre y de sexualidad feroz que estas criaturas que habitan los fríos espejos. Y a propósito de espejos: nunca pudieron

5 Pizarnik sostiene que: "Desnudar es propio de la Muerte. También lo es la incesante contemplación de las criaturas por ella desposeídas. [...] Pero, ¿quién es la Muerte? Es la Dama que asola y agosta cómo y dónde quiere”. 
aclararse los rumores acerca de la homosexualidad de la condesa, ignorándose si se trataba de una tendencia inconsciente o si, por lo contrario, la aceptó con naturalidad, como un derecho más que le correspondía (Pizarnik párr. 22).

Erzébet Báthory evidencia, a lo largo del texto, una serie de rasgos que pueden interpretarse a partir de una conducta homoerótica. El propio peso de su apellido, Báthory, la sitúa en el marco de una familia que asume el derecho a gozar libremente de otros/as ${ }^{6}$. De allí que el texto subraye la relevancia de la imagen del escudo familiar, los dientes del lobo, pues: “[...] los Báthory eran crueles, temerarios y lujuriosos. Los numerosos casamientos entre parientes cercanos colaboraron, tal vez, en la aparición de enfermedades e inclinaciones hereditarias: epilepsia, gota, lujuria" (Pizarnik párr. 15, cursivas mías). Así, estamos frente a una mujer que se arroga la potestad de disfrutar, plenamente, de los cuerpos de otros/as sin mediar ninguna clase de restricción. Incluso en la tortura de las mujeres es posible apreciar un cierto componente erótico que subraya la condición sexual de la aristócrata húngara:

Durante sus crisis eróticas, escapaban de sus labios palabras procaces destinadas a las supliciadas. Imprecaciones soeces y gritos de loba eran sus formas expresivas mientras recorría, enardecida, el tenebroso recinto. Pero nada era más espantoso que su risa. (Resumo: el castillo medieval; la sala de torturas; las tiernas muchachas; las viejas y horrendas sirvientas; la hermosa alucinada riendo desde su maldito éxtasis provocado por el sufrimiento ajeno.) [...] sus últimas palabras, antes de deslizarse en el desfallecimiento concluyente, eran: “¡Más, todavía más, más fuerte!” (Párr. 12).

Ahora bien, la narradora del texto entrega diversos detalles que parecen mostrar las inclinaciones lésbicas de Erzébet Báthory. De esta forma, La condesa sangrienta se hace cargo de la ola de rumores que parece revelar el componente homosexual de la personalidad de Erzébet Báthory:

Luego, algunos detalles, son obviamente reveladores: por ejemplo, en la sala de torturas, en los momentos de máxima tensión, solía introducir ella misma un cirio ardiente en el sexo de la víctima. También hay testimonios que dicen de una lujuria menos solitaria. Una sirvienta aseguró en el proceso que una aristocrática y misteriosa dama vestida de mancebo visitaba a la condesa. En una ocasión las descubrió juntas, torturando a una muchacha. Pero se ignora si compartían otros placeres que los sádicos (Párr. 23).

La indeterminación sexual/textual empleada por Pizarnik pone de manifiesto, en el prisma de Molloy, la resistencia del closet de Pizarnik: “[... ] el espejo en que se refleja (y

6 Considero esta nomenclatura debido a que Báthory estuvo casada con Ferencz Nadasdy, quien es catalogado en el texto como "[...] un guerrero de extraordinario valor". 
a la vez se reflexiona sobre) el lesbianismo es también un espejo borroso y confuso. Tan pronto registra algo, lo vuelve equívoco: así, por ejemplo, el lesbianismo de la condesa es un rumor, nunca se lo verificó" (364). Bajo esta perspectiva de análisis, es posible sostener que lo que en Pizarnik es incierto y brumoso, en Bolaño es explícito y palpable.

\section{Las dos caras del espejo}

Roberto Bolaño construye un episodio en 2666 que alude, en múltiples sentidos, a La condesa sangrienta. Los relatos protagonizados por las aristócratas europeas dan cuenta de una brutalidad que las llevas hasta el exceso. Mientras Pizarnik plantea como Báthory necesita de la muerte para alcanzar cierto placer sexual, Bolaño muestra como Von Zumpe experimenta el agobio y los gemidos propios de la muerte en la búsqueda del goce. Vida y muerte o muerte y vida parecen fusionarse en los personajes de Pizarnik y Bolaño. Ambas dan rienda suelta a una violencia fundamental, asentada en el exceso de vida en Von Zumpe y en el exceso de muerte de Báthory. Antes, establecí que con la noción de "violencias fundamentales" Bataille se refiere al erotismo, sin embargo, bien podría referirse a la tortura. El mal y el erotismo parecen conectarse a través de la fuerza y la crueldad desplegada en el goce del cuerpo en las obras de Pizarnik y Bolaño.

A partir de la mirada de reconciliación textual propuesta por Aldridge, Clements, Wellek y Warren es posible sostener que existen una serie de convergencias entre el fragmento de 2666 y La condesa sangrienta, debido a que los dos textos trabajan con la figura de una aristócrata europea empoderada y hermosa, que hace valer, en todo momento, los privilegios y los derechos que les otorga su posición social. Se suma, a lo anterior, la presencia de un espacio en común: la región de los Cárpatos. En este sentido, no solo es interesante el halo de horror que comparten los libros de Bolaño y Pizarnik sino las construcciones arquitectónicas en las que se mueven los personajes, tanto las presencia del laberinto como del castillo juegan un rol primordial en el desarrollo de la perversión y de la erótica en los textos.

Desde la perspectiva de Gilbert Chaitin es posible apreciar las diferencias que se producen en el tratamiento del horror y del erotismo en las obra de Pizarnik y Bolaño. La condesa sangrienta y el suceso del castillo de Drácula de 2666 realizan un doble juego de irradiación y difuminación en el tratamiento del horror y del erotismo. El ensayo poético de Pizarnik enfoca su mirada en la realización del mal, especialmente a través de las múltiples torturas a las que Báthory somete a sus doncellas y, en cambio, solapa el tratamiento del erotismo, abordando, de manera soterrada, el lesbianismo de la condesa. Bolaño invierte el procedimiento de la poeta argentina: exhibe en primer plano la lujuria de Von Zumpe y Entrescu y, por el contrario, desenfoca el horror de la Segunda Guerra Mundial, dejándolo fuera de los acontecimientos dionisiacos del castillo de Transilvania. 
Pizarnik y Bolaño construyen, en definitiva, textos que apuntan a traspasar los límites. Ambos desean romper con las formas de representación de Eros y Ker en la narrativa hispanoamericana, persiguiendo la consumación de la brutalidad. Asimismo, detentan una voluntad de transgresión en el plano estético y estructural. 2666 y La condesa sangrienta penetran en las delicias y el horror para abrir nuevas rutas en las letras continentales.

\section{Referencias}

Bataille, Georges. El erotismo. Trad. Antoni Vincens. Barcelona: Tusquets, 1985. Medio impreso.

---. La literatura y el mal. Madrid: Taurus, 1959. Medio impreso.

Barthes, Roland. El placer del texto. México: Siglo XXI, 2007. Medio impreso.

Bolaño, Roberto. 2666. Barcelona: Anagrama, 2004. Medio impreso.

Candia, Alexis. “Todos los males el mal. La 'estética de la aniquilación’ en la narrativa de Roberto Bolaño". Revista Chilena de Literatura 76 (2010): 43-70. Medio impreso.

Chaitin, Gilbert. "Otredad. La literatura comparada y la diferencia”. En La literatura comparada: principios y métodos, María José Vega (ed.). Madrid: Gredos, 1998. 34-55. Medio impreso.

Deleuze, Gilles. Coldness and cruelty. Masochism. New York: Zone Brooks, 1989. Medio impreso.

Franco Carvajal, Tania. Literatura Comparada. Buenos Aires: Losada, 1998. Medio impreso.

Galdo, Juan Carlos. “Fronteras del mal / genealogías del horror: 2666 de Roberto Bolaño". Hipertexto 2 (2005): 23-34. Medio impreso.

Hesíodo. El escudo de Heracles. México: Porrúa, 1976. Medio impreso.

Molloy, Sylvia. "De Safo a Baffo. La diversión de lo sexual en Alejandra Pizarnik". En Sexo y sexualidades en América Latina. Daniel Balderson y Donna J. Guy, compiladores (eds.) (357-367). Buenos Aires: Paidós, 1998. Medio impreso.

Martínez de Mingo, Luis. “2666 personajes en busca de destino”. Roberto Bolaño. Estrella cercana. Ensayos sobre su obra. Augusta López Bernasocchi y José Manuel López de Abiada (eds.). Madrid: Verbum, 2012. Medio impreso.

Monzón, Isabel. Báthory. Acercamiento al mito de la Condesa Sangrienta (2008). www. isabelmonzon.com.ar. Fecha de ingreso: 10 de septiembre de 2014. Sitio web.

Negroni, María. “Alejandra Pizarnik: Melancolía y cadáver textual”. Inti 52-53 (2000): 169-178. Medio impreso.

Pizarnik, Alejandra. La condesa sangrienta (2008). http://www.lacoctelera.com/myfiles/ modernistas/Alejandra\%20Pizarnik\%20-\%20La\%20Condesa\%20Sangrienta. pdf. Fecha de ingreso: 15 de septiembre de 2014. Sitio web. 
Toro Ballesteros, Sara. Un híbrido de horror y belleza: La condesa sangrienta de Alejandra Pizarnik. Letral 8 (2012): 99-107. Medio impreso.

Sichére, Bernard. Historias del mal. Barcelona: Gedisa, 1996. Medio impreso.

Stoker, Bram. Drácula. Trad. Mario Montalbán. Barcelona: Plaza \& Janés, 2000. Medio impreso.

Weeks, Jeffrey. El malestar en la sexualidad. Significados, mitos y sexualidades modernas. Trad. Alberto Magnet. Madrid: TALASA, 1993. Medio impreso.

Vega, María José. La literatura comparada: principios y métodos. Madrid: Gredos, 1998. Medio impreso.

Wellek, René. Historia de la crítica moderna. Madrid: Gredos, 1973. Medio impreso.

Recibido: 08 julio 2014

Aceptado: 09 julio 2015 